should really commence when the patient is first received at the sanatorium--that is, that his future should be considered from the outset of his treatment and all efforts should be concentrated upon his return to wage-earning capacity, so that before he leaves the sanatorium he should be capable of doing a full day's work. Dr. McConnel also outlines schemes for the organisation of after-care, and his suggestions are practical and useful.

Dr. Egbert Sumner Verdon has received the authority of His Majesty the King to accept and to wear the Insignia of Commander of the Hafidian Order conferred upon him by the Sultan Mulai-Abd-el-Hafid of Morocco. Dr. Verdon was physician to the Court of the Sultan. The undermentioned gentlemen have received the authority of His Majesty the King to accept and to wear the decorations which were conferred on them by His Majesty the Emperor of China by an Imperial Edict dated Feb. 6th last-viz. : Order of the Double Dragon : the Insignia of the First Class of the Third Grade to Mr. Dugald Christie, C.M.G., F.R.C.P. \& S. Edin., medical officer for the prevention of plague, Mukden Station; Insignia of the Second Class of the Third Grade to Mr. Alexander Russell Young, L.R.O.P. \& S. Edin., L.F.P.S. Glasg., and Mr. David Dickson Muir, L.R.C.P. \& S. Edin., L.F.P.S. Glasg., medical officers for the prevention of plague, Mukden Station; and the Insignia of the Third Class of the Third Grade to Robert John Gordon, M.A., M.B., B.Ch., of the Irish Presbyterian Mission.

\section{AFTER-CARE UNDER THE NATIONAL INSURANCE ACT. ${ }^{1}$}

BY H. W. McConnel, M.A., M.B. Cantab., M.R.C.S. Eng.

In the last two years great advance has been made in the matter of after-care throughout the country. Two years ago less than half of the sanatoriums in England considered after-care necessary, or at all events they did nothing in the matter; but now the great majority approve of the principle at least, and more than three-quarters have actual after-care of one sort or another in operation. Still there are some who hold out.

This being so, it may be well to set forth shortly the object of after-care. It is to help the patient to help himself after he leaves the sanatorium, to see that he continues to carry out the lessons he has learnt, not only as regards himself, but also as regards his family and his surroundings ; and to help him to meet the troubles of his life which he is sure to encounter when he starts earning his livelihood again. It is -useless, and a waste of public money, to go to the great expense of sanatorium treatment to restore a patient to good health again and to teach him how to keep well, and then to do nothing more than stand aside and allow him, through want of knowledge or stupidity, to slip back once more among the unemployed or unemployable, a burden to himself and his friends, and to the local rates.

The patient's future should be considered from the time he enters the sanatorium ; his after-care should be anticipated and should be borne in mind all through his stay 'there.' At the sanatorium -I am taking an ideal case where after-care is adequately and satisfactorily carried out, an ideal which is never quite reached in any one institution, some failing in one point and some in another-the patient - is taught that arrest of the disease and a return to wageearning capacity form the object of his stay, and he is shown that work is an essential part of the treatment; he is filled with hope as to his future, and he is not allowed in any way to develop the habits and manners of the loafer. As soon as he is capable he is put to little jobs in and about the place, at first very light, but gradually increasing in severity with his increasing capacity; and so he is gradually

1 Abstract of a paper read before the Manchester Tuberculosis Congress, June, 1912. brought before he leaves to do a full day's work and is turned out hard and capable.

The difficulties which meet a patient and in which aftercare is so useful fall into two heads: (1) those that are within the patient's own control; and (2) those which are not. Into the first category come disobedience to the rules and the recommendations when at the sanatorium, and also the not following out, when he leaves, the lessons he has learnt there. Into the second category come the troubles and difficulties due to incapacity on the one hand, and to the fear of infection on the other-I mean the fear that he will infect others which is apt to be in the minds of his employers and fellow employees.

All these difficulties can be met in a large measure by after-care. As regards the first, patients are not nearly so likely to be careless of themselves or of others when looked after-they are much more likely to be casual and to let things slide if left alone. And as regards the second, after-care workers can gradually weld the public mind and show that the risk from an ex-patient who has had sanatorium training is almost nil, and is as nothing compared with that from a consumptive who has stayed at home and has hushed up his disease in order not to attract the notice of others through fear of losing his work.

After the patient has been at the sanatorium for a time. and the resident medical officer has been able to sort his case and his capacity, his employment and its surroundings are inquired into; and in view of his past and its possibilities, and with due consideration to his present condition, suggestions and recommendations are made as to his future. If he is a good case and capable of work, efforts are made to arrange for a definite job for him to take up when he leaves the sanatorium; and finally, just before his departure, further advice is given him as to his future. Thus he leaves in as good health as his case allows, primed with information and full of hope for the future; and thus, passing out from the sanatorium and from those interested in him there, he comes under the influence of the after-care committee proper.

And it is here at this point of his career that there is apt to be a break in the satisfactory continuity of his treatment-i.e., in the transition from the sanatorium back to those who have sent him there-and it is to help this that the after-care committee of the National Association for the Prevention of Consumption made last year a very valuable suggestion. They recommended that a printed form, setting out some details of his case and adding the advice that had been given him at the sanatorium, should be sent to those interested in him before he came there and to whom he returned, in order that they might know what had been recommended. This suggestion has been sent to all artisan sanatoriums and will, I hope, do much to remedy a very obvious difficulty.

The happy result at the sanatorium is aided in two ways. First, by the working patients scheme, under which some of the patients are kept on at the sanatorium for a further period as part of the temporary staff of the institution, doing definite duties, but still under strict treatment. This gives them a further time to get well and hard, and a further opportunity to find a suitable job to go to when they leave. Secondly, by lectures and advice. In this way the patient is taught something about the rationale of his treatment and how to keep well afterwards, and what to avoid and what to do.

Sanatoriums at present may be divided into two classes: (1) subscription-supported; and (2) rate-supported. In general terms the features of the subsoription-supported sanatoriums are enthusiasm and a great deal of voluntary work; in fact, in most cases it is the energy of a few enthusiasts which starts the sanatorium and carries it along. Money is rather short and is made to go as far as possible both in building and in administration; it is these sanatoriums that we have to thank for finding out how best to build, equip, and maintain an institution at the least possible cost.

As regards after-care, this is done mostly by a local committee in the neighbourhood of the sanatorium-first, because the enthusiasts who run it live near; and secondly, because, as the patients' homes are usually at a distance and they are difficult to follow, it is easier, though not so effectual, to after-care them before they leave the sanatorium. This being so it follows that a great deal of stress 
is laid upon the sanatorium part of the after-care-that is, on the working patients scheme and the lectures and the educational talks, and the patients have often to'be left to self-care after they leave rather than to the labours of a properly organised after-care committee. Patients, of course, are asked to report, and some efforts are made to keep in touch with them later.

In the rate-supported sanatoriums, on the other hand, matters move more slowly, and there is often long consideration before action is taken, but when it is 'money is granted and is certain both for the building and for the maintenance. The medical officer of health is usually in charge of these sanatoriums. He is already a busy man, and local authorities have not grasped how much work a sanatorium demands, or have not appreciated that no man can do more than a certain amount properly. The result is that unless the medical officer of health happens to be extraordinarily keen or blessed with superhuman energy, there is a danger that some of the work is skimped, and amongst other things after-care is easily passed over. In these ratesupported sanatoriums most of the patients are local, so that a local after-care committee often gets better results than can be expected in subscription-supported sanatoriums with patients from a distance. There is, however, usually little money available for this after-care, and so the work is often handicapped.

As examples of subscription-supported sanatoriums I will take Kelling, Blencathra, and Daneswood-they each have peculiarities in their after-care ; and then $\mathbf{I}$ shall mention a few instances of rate-supported institutions.

Kelling is in Norfolk and has 70 beds. It has been open for ten year and has done much pioneer work, both in sanatorium building and in the working patients and after-care schemes. Sixteen men and three women working patients are kept on, doing work of various sorts in and about the place. One fetches milk from a dairy three miles away, one looks after the stable, another runs the acetylene gas plant and the pump for the well water, two or three are carpenters, and several work in the garden. This working patients scheme is found specially applicable to the single men or women who have no home ties.

At Kelling the organised work in the sanatorium is under a special At kelling the organised work in the sanatorium is under a special officer called the overseer, subject, of course, to the control of th resident medical officer. All sanatoriums are recommended to have such an officer, as he saves the resident medical officer much non-
medical work, and ensures that the work is really properly done and that there is no loafing.

As regards after-care Kelling has been fortunate enough from its As regards after-care Kelling has been fortunate enough from it commencement to secure the honorary services of a retired medical
man to push this side of the treatment. Last year at Kelling 70 men man to push this side of the treatment. Last year at Kelling 70 men and 36 women cases were considered: four men and five women became occupations or similar ones under bettered conditions, seven took up new work, 13 men and six women were unfit, and six failed to ge work. Notes are sent to those interested in the cases after they leave, but it is impossible, as few of the patients live near Kelling (some com even from the Isle of Man), to do more than this. The patients, how ever, are always welcomed if they can call again, and cards are sen round at Christmas time to all that have been at the sanatorium to ask how they are. The after-care at Maltings Farm and at Maitland Sanatoriums is done much in the same way as at Kelling.

Blencathra receives help from the Charity Organisation Society Blencathra is in Cumberland, and its patients mostly are Cumbrians the after-care work proper is chiefly seen to by the Carlisle Charity Organisation Society, and usually with great benefit. Many cases struggling on with unsuitable work have been helped to healthie surroundings, and patients showing signs of relapse are noted by the visitors. Ex-patients are urged to come

At Bellefield the after-care, with its graduated labour at the sanatorium and its most excellently organised ladies' auxiliary committee, is carried on in the same way and on the same lines as at Blencathra, and with most excellent results.

At Daneswood the conditions approach to the ideal, and what might be obtained under a rate-supported sanatorium, for there are a sufficiency of money and great enthusiasm. Daneswood is in Bedfordshire, and only takes patients of the Jewish persuasion; it is supported by private subscriptions and by the Jewish Board of Guardians. Most of the patients come from London and return to London, and both before and after their visit to the sanatorium are under the control of
the health committees, who refer the cases to the after-care comthe health committees, who refer the cases to the after-care comby this after-care committee, who find new work for their cases or by this after-care committtee, who find new work for their cases or making use of the Jewish love of barter, and as they find the money are in a position to demand obedience in the home and its surroundings. at in a position to demand obedience in the home and its surroundings. At the sanatorium the housework and the digging, \&c., are done by patients, and after they leave there is always some kind friend to take
them in hand. If the conditions that obtain at this Jewish sanatorium were found elsewhere the question of after-care would be easily solved.

I may specially note that the after-care committee at Daneswood carry on their work near the patient's home and away from the sanatorium, and this is rendered possible because most of the patients come from the same neighbourhood. The after-care committee is kept in touch with the findings of the resident medical officer at the sanatoriums by a monthly visit there of their secretary, when every case that
Now to take a few instances of after-care at rate-supported sanatoriums.

Salterly Grange (Cheltenham).-This institution is under the control of the Birmingham Health Department. Advice is given at the sanatorium, and the patients are put on to work as soon as they are fit, either with the gardener, carpenter, or engineer. The after-care work proper is carried on by the medical officer of health and his health visitors. Tuberculin inoculations in full doses are continued and the patient regularly visited, and if relapse occurs the cases are sent back to the sanatorium.

At Macelesfield there is a recently started borough sanatorium of 10 beds under the medical officer of health, which, though most excellently carried out, is meant only for advanced cases, so the institution may be looked on as purely educational and preventive. There is no after-care committee, but the health visitors follow up the cases, and the relief associations also give food when wanted, A satisfactory leaflet is given to each patient on leaving.

At the Aitken Sanatorium in this county (Lancashire), with 50 beds, the matter of after-care' is still under consideration, waiting. I think, like a large number of institutions, till the Insurance Act comes into force. but every case on discharge is notified to the medical officer of health and is then referred to the health visitors. The services of the local Charity Organisation Society are otten called in.

At Bowden matters have advanced a little further; selected eases do light work, gardening, poultry farming, \&c., and after they leave the light work, gardening, poultry farming, de., and atter they leave the
sanatorium are visited by lady visitors who report to a committee if sanatorium are visi

At Maiden Law advice and education to the patient at the sanatoriums and self-care after he leaves are much trusted to, but there is also a ladies visiting committee.

There is one more point of interest discussed by various authorities, and that is whether the health visitors should be paid or not paid. The rate-supported institutions on the whole lean towards the former. while the subscriptionsupported sanatoriums prefer to rely in most cases on the latter, but I think that both may advantageously be combined. It may be found best to have a paid secretary and a special phthisis nurse, but there will always be room for the unpaid health visitor and Charity Organisation Society worker, who will become more and more skilled as they gain experience, and will always infect the whole scheme by their enthusiasm and individuality.

And now I come to the consideration of after-care under the Act. This is somewhat difficult, as there is not one word in the Act referring to after-care. This is a mistake, for the failure of many cases to keep well and their falling back into ill-health is due to the absence of after-care, and it would have been well to have marked its importance by at all events introducing the name into the Act. But the advisory committee, with $\mathrm{Mr}$. Waldorf Astor as chairman, have valiantly pressed forward its claims, and if the Insurance Commissioners and the Local Government Board can be duly impressed $w$ ith the importance of the recommendations on this point, sanatoriums will at once begin to show results which they have not hitherto achieved. It is an opportunity of the greatest moment, and one which should not be missed.

It would be of much benefit to the community if this representative meeting could, either through the advisory committee or directly, urge the Local Government Board to insist on a suitable and well arranged scheme of after-care as one of the necessary conditions when granting approval to any sanatorium seeking to take patients under the Act, or when giving. a grant of money for maintenance or for the establishment of a dispensary unit.

Now to turn to the recommendations of the advisory committee. I think that this committee would have been better advised to have used the term "after-care" in a wider sense than they have. They use the expressions "sanatorium benefit" and "sanatorium treatment" in wide sense-i.e., to treatment, not only in the sanatorium, but even in the patient's own home; so here it would have been well to have included in the term "after-care" anything and everything that would tend ultimately to the after-caring of the patient. I am sure that the advisory committee will agree to this, and $I$ invite their attention to it in their final report.

Again, in the interim report they state that disoretion should be used in after-care and publicity avoided because of the exaggerated fear of the infectivity of consumption among employers and fellow employees; this, I think, also is a mistake. The fear of infection is exaggerated, but a policy of fear of talking will not help to correct this. I think, on the contrary, that there should be much talk about it and employers shown that a man who has been to a sanatorium and who obeys its rules is not dangerous or infections.

With these two exceptions, I am fully in accord with the rest of the advisory committee's suggestions on after-care. 
Their main scheme of passing the patients on their way to a sanatorium first through a dispensary under a capable tuberculosis officer, and of then referring them back again to the dispensary on their discharge, is a very excellent one, and should meet with warm approval, for it ensures that every case is properIy considered, and it allows of the happy coöperation of voluntary care committees and of paid health visitors under the chief tuberculosis dispensary officer. It brings all these agencies into line and prevents overlapping of effort.

So under the Act the machinery for after-care should be as follows :-

1. At the dispensary the chief tuberculosis dispensary officer, who first sees the case and sencts him for admission to the sanatorium.

2. At the sanatorium. (a) The resident medical afficer, who treat the case and gives lectures and teaching and also arranges for the working patients scheme. (b) A small honorary after-care committee, containing if possible a retired medical man, with a paid, secretary. This committee, called "The Sanatorium After-Care Committee, would meet at intervals, and with the full concurrence and assistance of the resident medical officer would interview each patient and advise as to his future work and mode of life. These recommendations would be written down and sent, when the patient left the sanatorium, to the chief tuberculosis dispensary officer.

3. At the dispensary. The after-care committee proper, which might be called "The Dispensary After-Care Committee," and which would be perhaps a subcommittee of the Insurance Committee, with power to add to their numbers. This committee, which should be small, would act in full conjunction with the chief tuberculosis dispensary officer, whose advice and direction they would follow, and dispensary osistance or instrumentality of the they would follow, an with the assistance or instrumentality of the special phthisis nurse, health visitors, and local Charity Organisation Society, dc., would keep in touch with the patient, visit at his home, see that he carried out th rules and recommendations learnt at the sanatorium, and generally would a what they could to help him. Latitude should be given in the formation of this committee, so as to include those who are specially interested or skilled in this work in each neighbourhood, but it should be a sine quâan not that should act in conjunction with, and under the direction of, the chief tuberculosis dispensary officer, who would be the centre of ail this movement. If the sanatorium was situated near the patients' homes it might be desirable for the Sanatorium After-Care Committee and the Dispensary After-Care Committee to be one and the same.

In conclusion, I should like to repeat that the outlook for the after-care side of treatment has never been so bright as it is under this Act, if properly administered. If a small grant of money is allowed for the purpose, and if the voluntary and paid agencies are linked up around the tuberculosis dispensary officer and the dispensary, a great deal of good should be done, and most of the present difficulties in the matter of after-care should be overcome.

But it must be remembered that each case must be treated and attended to on its own merits, and the individuality of each case must be fully considered; so it is desirable, on the one hand, to keep the committees small and to allow as full a play as possible to the enthusiasm of the few who are really interested and who really know; and, on the other hand, each patient must be made to feel that individual effort is necessary on his part. and he must not be allowed for one moment to think that if he does nothing everything will be done for him. For the object of after-care is not to keep a large body of loafers alive, but rather to help those who help themselves, and to meet if possible in some way the handicap of their disease.

Foreign UNIVERSTTY INTELLIGENCE.Berne: Dr. L. Schneider has been recognised as privatdocent of Medicine; and Dr. J. W. Schürmann and Dr. M. G. Rothemund as privat-docesten of Hygiene and Bacteriology.-Breslau: Dr. P. Heinrichsdorff has been recognised as privat-docent of General and Pathological Anatomy.-Freiburg: Dr. Leopold Küpferle has been recognised as pricat-docent of Medicine.-Genoa: Dr. E. Arman, of Pisa, has been recognised as privat-docent of Dermatologr.-Kharknff: Dr. Menschikoff, of Kazan, has been appointed Extraordinary Professor of Pædiatry. - Kiel : Dr. Hans Oloff, naval staff surgeon, doeent of Ophthalmology in the Naral Medical College, has been granted the title of Professor.-Limoges : Dr. Raymond has been promoted to the chair of Histology.-Moscon: Dr. B Venglorski has been appointed Extraordinary Professor of Operative Medicine and Topographical Anatomy. Philadelphia (Jefferson Medieal College): Dr. Thomas McCrae, of the Johns Hopkins University, Baltimore, has been appointed "Professor of Cliraical Medicine, in succession to Dr. 'Wilson, resigned.-Rome: Dr. Fausto Constatini has been recognised as privat tooent of Neurology and Psychiatry. - Sienna: Dr. Fillipipo Neri, of Pisa, has been recognised as pricat-dooent of Hygieme and Medical Police.

\section{HEALTH OF EUROPEANS IN FHST AFRICA.}

By ARTHUR E. HoRN, M.D., B.Sc. LoNm,

MEDICAL OFFICER, WEST AFRICAY MEDTCAL ST A PT,

A sHoRT time ago I called attention in THE IANCSert ${ }^{1}$ to the recent vital statistics of non-native officials in West. Africa presented to Parliament by the Colonial Office. Similar statistics dealing with the years 1910 and 1911 have now been prepared for European officials serving: in the British Dependencies of East Africa, including the East Africa Protectorate, Uganda, Nyasaland (formerly known as British Central Africa), and Somaliland. They are of interest in allowing, to some extent, of comparison of health conditions, not only between the different East. African Dependencies themselves, but also between East Africa as a whole and British West Africa-bearing in mind, however, the important fact that as regards the newer East African possessions the statistics apply solely to the last two years, whereas in West Africa they are concerned with the nineyears 1903-11 inclusive.

The Tear 1910.

The information available for the year 1910 is inconplete in some respects, notably as regards the age-distribution of officers, but this information is being collevterl as officers come on leave, and in future returns should be more complete.

Particulars of officials who left the service Anning this year are included in the following return :--

TABLE I.-Return shoming Deaths, Invalidings, so.

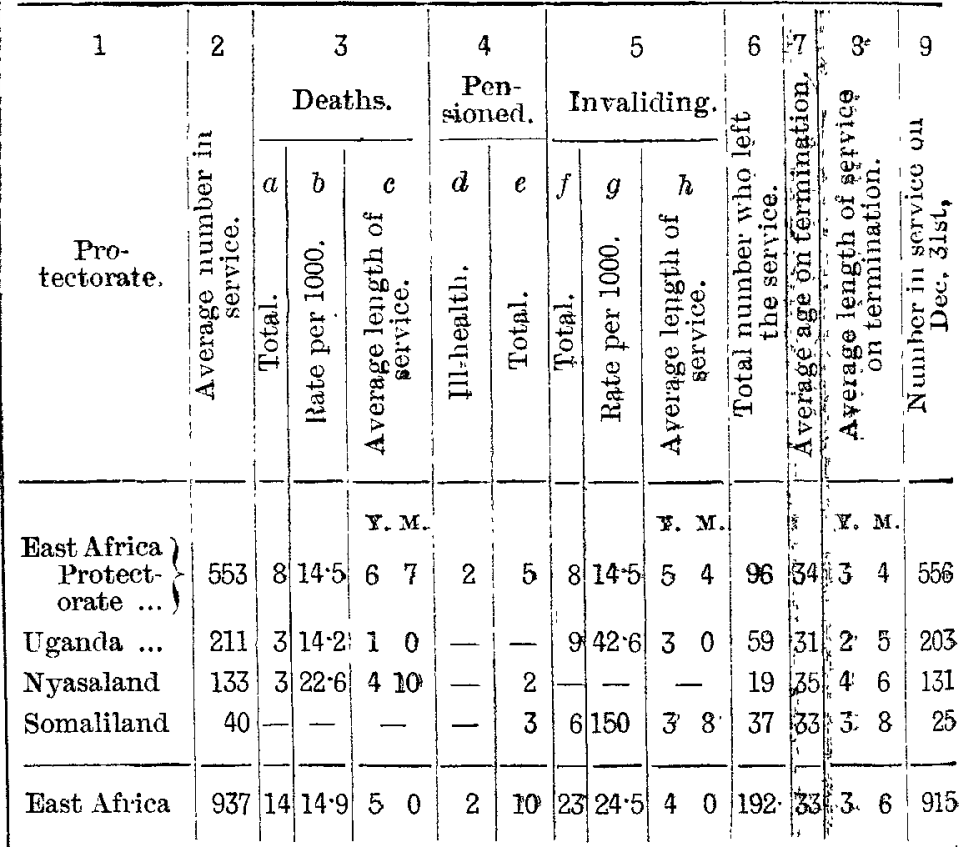

It will be noticed that the total of Column 6 of this table is less than the actual total of the figures given for the separate Protectorates. 'This is accounted' for by the' transfer of officers from one Protectorate to another.

7)eath-rate, 1010. - The total death-rate for the year was 14.9 per 1000 . No deaths occurred from causes: other than disease. The canses of death were as follows:-East Ifrica Protectorate.-Malaria and hyperpyrexia, 1 ; malaria, 1 ; cancer, 1 ; chronic bronchitis and heart faifure, 1 ; abscess of liver, 1 ; bursting of blood-vessel, 1 : leprosy, 1; rhenmatic fever, 1. Uzanda,-Blackwater fever, 2 ; unknown, 1. Nyasaland.-Blackwater fever, 1 ; gastroenteritis, 1 ; unknown, 1.

Invaliding-rate, 1910.-. The total invaliding rate for the year was 24.5 per 1000 . The causes of invaliding were as follows:-East Ifrica Protectorate.-Syphilis, \& ; progressive visceral changes, 1 ; sciatica, 1 ; malaria, 1 ; insanity, 1 ; heart troubles, 2 ; abscess of. liver, 1 . Uganda.-Dislocated shoulder, 1 ; gonorrhcea, 1 ; digestive troubles, 1 ; dyspepsia and heart trouble, 1 ; boils, 1 ; blackwater fever, 1 ; nervous breakdowns, 3 . . Samadïland.-

1 See Health of Europeans in West Africa, Thi LAroter, May 18th, 1912 , p. 1356. 